\title{
Pequenos golpes e astúcias sutiS \\ a figura do trickster na série Blanche white mysteries, de Barbara Neely
}

\section{SMOOTH OPERATIONS: THE USES AND TACTICS OF THE TRICKSTER FIGURE IN BARBARA NEELY'S BLANCHE WHITE MYSTERIES}

Carla de Figueiredo Portilho*

Universidade Federal Fluminense

\begin{abstract}
RESUMO
As práticas cotidianas - especialmente os pequenos golpes e astúcias que caracterizam a figura do trickster - marcam presença na série Blanche white mysteries, de Barbara Neely, objeto de estudo deste artigo. Tomando como base para argumentação a teoria de Michel de Certeau sobre a práxis cotidiana, desenvolvida em A invenção do cotidiano, busca-se discutir de que forma essas práticas se re-significam no embate entre o centro de poder e grupos "invisíveis", além do seu papel político como uma tática de resistência empregada como oposição a práticas socioculturais dominantes.
\end{abstract}

PALAVRAS - CHAVE

Romance policial, contraliteraturas, periferia

A tática é a arte do fraco.

Michel de Certeau ${ }^{1}$

Em A invenção do cotidiano, Michel de Certeau dedicou-se a analisar as práticas cotidianas do homem comum como um meio de opôr resistência às práticas socioculturais dominantes. Distinguindo as artes de fazer entre estratégias e táticas, ${ }^{2}$ De Certeau define estratégias como uma manipulação das relações de força que possibilitam o estabelecimento de um lugar próprio de poder; as táticas, por outro lado, são as ações determinadas exatamente pela ausência de poder, um não-lugar que só se realiza no espaço do Outro e em relação a ele, aproveitando-se das circunstâncias para alcançar

\footnotetext{
* carla_portilho@id.uff.br

${ }^{1}$ CERTEAU. A invenção do cotidiano: 1. Artes de fazer, p. 101.

${ }^{2}$ CERTEAU. A invenção do cotidiano: 1. Artes de fazer, p. 97-102.
} 
qualquer possibilidade de ganho. São maneiras outras de fazer, que imprimem novos significados a códigos preestabelecidos e que, por meio de pequenas astúcias e golpes, re-significam essas práticas. As táticas são modos de fazer que funcionam como uma cultura diferente dentro da cultura dominante; embora aparentemente estejam em conformidade com o que é imposto pelo poder, essa conformidade se restringe à superfície. Enquanto as estratégias são sustentadas pelo poder, as táticas visam a resistir a esse mesmo poder. Portanto, partindo-se do pressuposto de que as práticas cotidianas podem constituir uma forma de resistência de culturas subalternas ao poder dominante, sua presença em romances produzidos fora do centro hegemônico adquire um propósito político: constituem uma tática por meio da qual as comunidades marginalizadas representadas buscam se (re)apropriar de um espaço cultural, político e socioeconômico, adquirindo novos significados no espaço de confronto entre o centro de poder e a periferia. Considerase que o poder, amarrado às aparências e à sua visibilidade, não se pode permitir mobilizar seus meios para os efeitos da astúcia; o fraco, ao contrário, muitas vezes tem na astúcia sua única possibilidade, um último recurso. Por meio de golpes e astúcias, usando a criatividade e sabendo aproveitar as ocasióes, o homem comum aproveita as brechas que se abrem no sistema dominante para buscar seu próprio espaço.

No âmbito deste ensaio, essa prática é representada pela faxineira afro-americana dublê de detetive, batizada, de forma deliciosamente irônica, como Blanche White, e suas características tipicamente associadas ao trickster. Blanche protagoniza a coleção policial Blanche white mysteries, de Barbara Neely, que conta até o momento com quatro romances: ${ }^{3}$ o primeiro volume foi publicado em 1992 com o título de Blanche on the lam, e a ele seguiram-se Blanche among the talented tenth (1994), Blanche cleans up (1998) e Blanche passes go (2000). O nome da protagonista, que provoca desde leves constrangimentos a sonoras gargalhadas nos outros personagens, já sinaliza que esta não é uma série policial descompromissada. Ao batizar sua protagonista negra com um nome que significa "branco" duas vezes, Barbara Neely atrai a atenção do leitor para as questões de cor e raça entremeadas no enredo da série. ${ }^{4}$ Neely afirma que sua intenção, ao escolher esse nome para sua protagonista, foi deixar bem claro para o leitor o fato de que se trata de uma série com intenções políticas, que pretende abordar questões relativas à raça: ${ }^{5}$

Algo de que me acusaram no passado, em outras situações de trabalho, foi de dizer algo às pessoas, então dizer-lhes que eu havia dito isso a elas e depois dizer-lhes o que eu já havia dito, sempre repetindo tudo de novo. Com Blanche White, era: bem, se vocês não entenderam que este é um livro sobre raça, deixe-me dar-lhes esta mulher grande e negra cujo nome significa branco - duas vezes. ${ }^{6}$

\footnotetext{
${ }^{3}$ Não há informação no site oficial referente à série, disponível em <http://www.blanchewhite.com > , se a autora pretende dar continuidade à obra, embora sejam frequentes os pedidos de leitores ávidos por novas aventuras de Blanche, na seção "Feedback".

${ }^{4}$ Cf. SCHILLER. Between Afrocentrism and universality: detective fiction by black women, p. 29.

${ }^{5}$ GOELLER. An interview with Barbara Neely, p. 299-307. (Todas as traduções são minhas, exceto quando especificamente mencionado.)
}

${ }^{6}$ GOELLER. An interview with Barbara Neely. p. 301. 
Indo um pouco mais fundo na explicação oferecida pela autora, pode-se considerar que a carga de significado político do nome de Blanche White reside no fato de que, no conjunto, a presença dos dois nomes acaba por inverter o significado isolado de cada um deles. Esse significado não passa despercebido aos próprios personagens dos romances, como na cena em que Mattie Harris, uma famosa escritora feminista hospedada no mesmo resort que Blanche, levanta um brinde "à ironia da pessoa que a nomeou embora você deva passar maus bocados, Blanche White". ${ }^{7}$ Considerando a escolha dos dois nomes uma tática, na acepção de De Certeau, temos uma fórmula em que a soma dos negativos gera um resultado positivo, ou seja, Blanche anula White e vice-versa. Dessa forma, o uso alternativo que se faz dos dois nomes, isto é, a repetição de significados, ao invés de reforçar a noção de branco, acaba por descentrá-la, provocando um deslizamento nas próprias categorias branco/negro. ${ }^{8}$

Ao longo das investigações de Blanche, são constantes as referências à invisibilidade daqueles que estão à margem da sociedade, uma ideia que remete o leitor ao romance Invisible man, de Ralph Ellison, obra paradigmática do tema na literatura afro-americana. Trata-se de um "bildungsroman às avessas" - ao longo da narrativa, o protagonista, que narra sua história em primeira pessoa, percebe que, por ser negro, é invisível aos olhos da sociedade branca. Essa constatação é exposta ao leitor logo nas linhas de abertura do romance:

I am an invisible man. No, I am not a spook like those who haunted Edgar Allan Poe; nor am I one of your Hollywood-movie ectoplasms. I am a man of substance, of flesh and bone, fiber and liquids - and I might even be said to possess a mind. I am invisible, understand, simply because people refuse to see me. ${ }^{10}$

A narrativa do romance é circular - tanto o prólogo quanto o epílogo são ambientados no mesmo momento e no mesmo espaço, um buraco subterrâneo que serve ao narrador, a princípio, de esconderijo, e logo de moradia. Esse buraco é o porão abandonado de um edifício ocupado apenas por famílias brancas, situado nos limites do Harlem, onde ele vive secretamente, sem pagar aluguel, ouvindo blues, e usufruindo da potente iluminação fornecida por mais de mil lâmpadas mantidas com eletricidade

\footnotetext{
${ }^{7}$ NEELY. Blanche among the talented tenth, p. 27. "to the irony of the person who named you - although you must catch hell, Blanche White."Ao trabalhar com obras literárias em edições estrangeiras, optou-se por manter as citações na língua original de publicação, quando destacadas do corpo do texto, incluindo a tradução no pé de página, de modo a não privilegiar a tradução em detrimento do texto original do autor. Entretanto, usou-se a tradução quando as citações fazem parte de uma estrutura sintática em português.

${ }^{8}$ Cabe aqui, inclusive, tecermos conjecturas a respeito do nome da detetive, no sentido da dupla inscrição de "branco", associando-o ao costume do "double negative", tão difundido no Black English (como, por exemplo, na expressão "I ain't got no money"), sugerindo que o negro nos EUA precisa "negar duas vezes" para poder afirmar.

${ }^{9}$ Frank citado por LYNE. The signifying modernist: Ralph Ellison and the limits of double consciousness.

${ }^{10}$ ELLISON. Invisible man, p. 3. "Eu sou um homem invisível. Não, eu não sou um fantasma como aqueles que assombravam Edgar Allan Poe; nem sou um daqueles ectoplasmas dos filmes de Hollywood. Eu sou um homem de substância, de carne e osso, de fibra e líquidos, e poderiam dizer até que possuo uma mente. Eu sou um homem invisível, entendam, simplesmente porque as pessoas se recusam a me ver."
} 
desviada da companhia de energia. É a partir desse peculiar refúgio subterrâneo que ele conta a sua jornada.

O fato de que o personagem preenche o silêncio à sua volta com a voz de Louis Armstrong cantando "What did I do to be so black and blue?" é sintomático, pois o blues é um dos meios pelos quais o personagem re-significa a sua trajetória pelos paradigmas vividos pelo negro nos EUA. Como aponta Raymond M. Olderman, "o blues é uma expressão simbólica (...) [que] expressa todas as ambigüidades, contradições, possibilidades, esperanças e limitações que se encontram na circunstância humana." ${ }^{11}$ Ainda nas palavras de Olderman:

O narrador de Invisible man canta seu próprio blues ao nos contar a sua história, e ao cantar o blues ele descobre o significado do seu próprio ser e a natureza da sua realidade; é um conto que fala do crescimento da consciência individual e do crescimento da percepção.(...) Porque, novamente, no âmago do significado do blues encontram-se todas as ambivalências, esperanças, liberdades, limitações, possibilidades, e mistérios que repousam sob a pele do homem e sob a superfície do que o homem chama de realidade. ${ }^{12}$

Ao longo da jornada do protagonista, Ellison seguidamente expõe, reverte e destrói uma série de rituais, mitos, tradições e preconceitos sobre o negro nos EUA. ${ }^{13} \mathrm{Na}$ definição de Jeremy Weate, "a história que ele narra é, na superfície, um relato picaresco de tédio existencial, que mapeia as tragicomédias de fracassos na escola, em uma fábrica, na política radical e, por fim, no Harlem". ${ }^{14}$ Os capítulos iniciais apresentam um personagem passivo, cuja percepção de si próprio é moldada pelo mundo exterior - o fardo da dupla consciência de que trata DuBois. ${ }^{15}$ Conforme o desenrolar do enredo, o protagonista é levado à percepção de sua invisibilidade, à sua condição de mero instrumento para a sociedade branca, que não o enxerga como um indivíduo. É interessante ressaltar aqui uma observação de Weate a respeito da explicação oferecida pelo personagem para sua invisibilidade:

A invisibilidade, explica o Homem Invisível, ocorre como uma construção dos olhos interiores daqueles que se recusam a vê-lo. O Homem Invisível é invisível porque não é reconhecido como um ser humano.(...) [V]emos que por meio de uma redução metonímica inconsciente, as "pessoas" que se recusam a ver o Homem Invisível por meio das construções de seus olhos interiores são, de fato, pessoas brancas. O Homem Invisível aparentemente capitula e internaliza seu estado sub-humano ao reproduzir essa elipse no seu discurso: todas as "pessoas" são pessoas brancas. ${ }^{16}$

O raciocínio de Weate leva o leitor a concluir que ser negro em uma sociedade que apenas reconhece os brancos como humanos equivale a ser invisível, ${ }^{17}$ a premissa

\footnotetext{
${ }^{11}$ OLDERMAN. Ralph Ellison's Blues and Invisible Man, p. 142.

${ }^{12}$ OLDERMAN. Ralph Ellison's blues and Invisible Man, p. 143.

${ }^{13}$ OLDERMAN. Ralph Ellison's blues and Invisible Man, p. 144.

${ }^{14}$ WEATE. Changing the Joke: invisibility in Merleau-Ponty and Ellison, p. 12.

${ }^{15}$ DuBOIS. The souls of black folk. Ver capítulo 1: "Of our spiritual strivings".

${ }^{16}$ WEATE. Changing the Joke: invisibility in Merleau-Ponty and Ellison, p. 12-13. (grifos do autor)

${ }^{17}$ WEATE. Changing the Joke: invisibility in Merleau-Ponty and Ellison, p. 13.
} 
básica do romance de Ellison. Charles Mills explica que para que essa estrutura social se mantenha é necessário que a lógica normativa que a sustenta seja dissimulada:

A experiência branca é incrustada como normativa, e a incrustação é tão profunda que sua normatividade não é nem mesmo identificada como tal. Porque isso implicaria que as coisas poderiam ser de outro modo, enquanto é óbvio que esse é apenas o modo como as coisas são. A relação com o mundo que é assentada sobre o privilégio racial torna-se simplesmente $a$ relação com o mundo. ${ }^{18}$

Desse modo, a estrutura social da normatividade branca é naturalizada, escondendo os vários mecanismos por meio dos quais as pessoas são reduzidas a um estado subhumano com base apenas na cor da sua pele. ${ }^{19}$

Por fim, no epílogo do romance, o narrador assume uma postura mais atuante, no momento em que decide que é chegada a hora de abandonar a sua hibernação e sair do buraco:

And, as I said before, a decision has been made. I'm shaking off the old skin and I'll leave it here in the hole. I'm coming out, no less invisible without it, but coming out nevertheless. And I suppose it's damn well time. Even hibernations can be overdone, come to think of it. Perhaps that's my greatest social crime, I've overstayed my hibernation, since there's a possibility that even an invisible man has a socially responsible role to play. ${ }^{20}$

Assim como o narrador-protagonista de Ralph Ellison, Blanche White também é uma personagem invisível nos lares brancos. A princípio, essa invisibilidade se traduz como uma supressão da individualidade - a sociedade branca não vê o negro, e essa cegueira torna-se ainda mais gritante no caso do empregado doméstico. Doris Witt aponta que os membros das classes socialmente privilegiadas aprendem a não ver os empregados domésticos, e estes, por sua vez, podem contribuir para permanecer despercebidos, ao usar o uniforme exigido pelos patrões ou ao portar os instrumentos característicos do seu trabalho, por exemplo. ${ }^{21}$ Duas passagens de Blanche on the lam ilustram bem o caso - na primeira, Blanche faz um comentário mordaz sobre uma patroa que exigia que os empregados usassem uniformes; na segunda passagem, ela se prepara para bisbilhotar o quarto de hóspedes da casa onde estava trabalhando, mas não sem antes preparar todo o aparato necessário a uma boa faxina:

\footnotetext{
${ }^{18}$ Mills citado por WEATE. Changing the Joke: invisibility in Merleau-Ponty and Ellison, p. 13. (grifo do autor)

${ }^{19}$ WEATE. Changing the Joke: invisibility in Merleau-Ponty and Ellison, p. 13.

20 "E, como eu disse antes, uma decisão foi tomada. Estou descartando a pele antiga e vou deixá-la aqui no buraco. Vou sair, não menos invisível sem ela, mas vou sair mesmo assim. E eu suponho que esteja mais do que na hora. Até as hibernações podem durar mais do que deveriam, pensando bem. Talvez seja este o meu maior crime social, ter hibernado por tempo demais, já que existe a possibilidade de que até mesmo um homem invisível tenha um papel socialmente responsável a desempenhar." (ELLISON. Invisible man, p. 581.)

${ }^{21}$ WITT. Detecting bodies: Barbara Neely's Domestic sleuth and the trope of the (in) visible woman, p. 170.
} 
Blanche was reminded of old lady Ivy, out on Long Island. She couldn't stand to see the help in regular clothes, either. Might mistake them for human beings. ${ }^{22}$

She lugged the vacuum and a bucket holding a feather duster, furniture polish, chamois, sponge, spray cleaner, and a long-handled brush up the back stairs. She had no intention of using all those items, but it looked good to have them. ${ }^{23}$

A invisibilidade, entretanto, apresenta também um lado positivo. Como lembra Ellison, ainda no prólogo de Invisible man, "às vezes é vantajoso não ser visto, embora na maior parte das vezes seja bem desgastante para os nervos". ${ }^{24}$ Tanto a cor da sua pele quanto o uniforme de empregada doméstica fazem Blanche passar despercebida, e é apenas por isso que ela pode "xeretar" sem ser incomodada. De acordo com Doris Witt, a invisibilidade do empregado doméstico é uma ficção que provê o disfarce ideal para os olhos curiosos, e Blanche frequentemente tira vantagem dessa ficção, ficando até mesmo frustrada quando, uma vez iniciada a investigação, seus patrões a "veem". ${ }^{25}$ Nancy Tolson, entretanto, lembra que ela se torna visível quando algum acontecimento nesse ambiente a ameaça ou ameaça um membro da família ou um amigo, e uma reação se torna necessária:

Que personagem literário seria melhor para adentrar o gênero policial senão uma empregada negra que conhece a casa melhor do que os seus próprios donos, que vê mas não é vista, e que nunca é questionada por abrir as gavetas? Ela não é detectada porque é invisível há anos e agora grita quando a sujeira de outros lugares além das janelas e das pilhas de roupas para lavar respinga nela própria ou nos seus. ${ }^{26}$

Em determinadas circunstâncias, portanto, vê-se que manter a invisibilidade é uma tática de sobrevivência, especialmente se aliada a uma aparência de submissão e docilidade. Trata-se de uma forma de Significar ${ }^{27}$ - ao invés de se disfarçar como um personagem completamente diferente de si própria, Blanche mergulha no estereótipo

22 "Ela também não suportava ver os empregados em roupas comuns. Poderia confundi-los com seres humanos." (NEELY. Blanche on the lam, p. 12.)

23 "Ela arrastou o aspirador e um balde com um espanador, o lustra-móveis, uma flanela, uma esponja, o limpador em spray e uma escova de cabo longo pela escada dos fundos. Não que ela tivesse a intenção de usar todos esses itens, mas dava uma boa impressão tê-los consigo." (NEELY. Blanche on the lam, p. 82.)

24 "It is sometimes advantageous to be unseen, although it is most often rather wearing on the nerves." (ELLISON. Invisible man, p. 3.)

${ }^{25}$ WITT. Doris. Detecting bodies: Barbara Neely's domestic sleuth and the trope of the (in) visible woman, p. 169.

26 TOLSON. The butler didn't do it, so now they're blaming the maid: defining a black feminist trickster through the novels of Barbara Neely, p. 75.

${ }^{27}$ GATES Jr. The signifying monkey: a theory of African American literary criticism. Henry Louis Gates Jr. aponta que Significar é um princípio da cultura afro-americana, uma tática por meio da qual se marca a diferença em relação à cultura branca - há uma imitação aparente, mas que revela ser uma subversão da estratégia dominante. De forma simplificada, Significar consiste em engajar-se em certos jogos retóricos, nos quais os falantes tomam um determinado significante e o esvaziam de seus conceitos recebidos para que possam preenchê-lo com seus próprios conceitos, rompendo assim a relação entre o significante e o significado. Uso aqui a inicial maiúscula para marcar que se trata do conceito de Signifying de Henry Louis Gates Jr., mantendo o padrão usado em The signifying monkey. 
da empregada negra, familiar aos seus patrões brancos, no qual ela pode se esconder da polícia com segurança. Rosemary Hathaway afirma que Blanche se engaja em um jogo entre os estereótipos que seus patrões brancos têm a seu respeito e sua própria consciência do poder e da proteção oferecidos por essa lacuna, esse espaço entre o significado superficial, percebido por eles, e o significado latente, do qual apenas ela está ciente. ${ }^{28}$ De acordo com Hathaway, "essa lacuna, na verdade, é onde ela escolhe se refugiar, porque a proteção metafórica que ela oferece é ainda mais segura do que a proteção literal da casa de veraneio". ${ }^{29}$ Blanche faz um uso tático dessa segurança e do poder latente do seu disfarce - ao "brincar" com as suposições dos brancos a seu respeito, Blanche pode subvertê-las, como no exemplo abaixo:

She (...) quickly slipped on the bright-eyed but vacant expression behind which she'd hid from the woman so far. Blanche had learned long ago that signs of pleasant stupidity in household help made some employers feel more comfortable, as though their wallets, their car keys and their ideas about themselves were all safe. Putting on a dumb act was something many black people considered unacceptable, but she sometimes found it a useful place to hide. She also got a lot of secret pleasure from fooling people who assumed they were smarter than she was by virtue of the way she looked and made her living. ${ }^{30}$

Ao se disfarçar como a imagem estereotipada do seu ofício, que muitos assumem ser a epítome da domesticidade dos negros, Blanche se aproxima da figura do trickster, ${ }^{31}$ uma figura ambígua, de certa forma contraditória, mais indefinida do que intrinsecamente boa ou má, e que ocupa um espaço à margem da sociedade - no caso de Blanche, um espaço de negociação entre a sociedade dominante e aqueles por ela dominados. É assim que ela tira vantagem da cegueira cultural da comunidade para investigar e por fim resolver os mistérios em sua cidade natal. Em suas próprias palavras, "foi assim que sobrevivemos neste país todo esse tempo, sabendo quando agir como se acreditássemos no que nos disseram e quando agir como se soubéssemos o que sabemos". 32

${ }^{28}$ HATHAWAY. The signifyin (g) detective: BarbaraNeely's blanche white, undercover in plain sight, p. 323-324.

${ }^{29}$ HATHAWAY. The signifyin(g) detective: Barbara Neely's blanche white, undercover in plain sight, p. 324.

${ }^{30}$ NEELY. Blanche on the lam, p. 16. "Ela (...) rapidamente assumiu aquela expressão vazia, mas de olhar brilhante, atrás da qual ela tinha se escondido da mulher até então. Blanche tinha aprendido há muito tempo que sinais de uma agradável estupidez nos ajudantes domésticos tranquilizavam alguns patrões, como se suas carteiras, chaves do carro e suas ideias acerca de si mesmos estivessem seguras. Desempenhar um papel de bobo era algo que muitos negros consideravam inaceitável, mas ela às vezes achava que era um lugar seguro para se esconder. E ela também sentia um prazer secreto ao ludibriar gente que achava que era mais esperta que ela, por conta de sua aparência e do modo como ganhava a vida."

${ }^{31}$ TOLSON. The butler didn't do it, so now they're blaming the maid: defining a black feminist trickster through the novels of Barbara Neely, p. 74.

32 "This is how we've survived in this country all this time, by knowing when to act like we believe what we've been told and when to act like we know what we know." (NEELY. Blanche on the lam, p. 73.) 
O trickster é, nas palavras de Renato Queiroz, "o herói embusteiro, cômico, ardiloso, pregador de peças, protagonista de façanhas". ${ }^{33}$ Como o trickster, Blanche se vale da astúcia e da rebeldia como meios para desafiar a autoridade e questionar a ordem vigente. Embora o trickster possa empregar tais características tanto de forma destrutiva quanto construtiva, Blanche se atém ao segundo modelo, pois seu objetivo primordial é encontrar uma saída para a situação adversa em que ela própria se encontra - caso não descubra o verdadeiro assassino, ela corre o risco de se ver acusada pelo crime. Em seu processo de investigação, muitas vezes os ardis são fundamentais para que ela alcance seu objetivo. No exemplo abaixo, seu objetivo era assegurar o respeito devido a uma mulher mais velha por parte de um rapazinho - branco, no caso:

Blanche hissed some broken Swahili and Yoruba phrases she'd picked up at the Freedom Library in Harlem and told the boy it was a curse that would render his penis as slim and sticky as a lizard's tongue. The look on his face and the way he clutched his crotch lifted her spirits considerably. Nina Simone's version of "I Put a Spell on You" came rolling out of her mouth in a deep, off-key grumble. ${ }^{34}$

Mesmo não tendo conhecimento de magia, feitiços ou maldições, Blanche age como se tivesse, e isso é o que realmente conta para impressionar seu interlocutor, que é branco e, portanto, provavelmente não teria nenhum conhecimento da tradição religiosa africana. Como o trickster, ela usa a ambiguidade a seu favor: ela é e não é, ao mesmo tempo.

Essa ambiguidade é um ponto de aproximação entre o trickster e o pícaro. O objetivo primordial do pícaro é fugir da pobreza, tornar-se um "homem de bem" - um aristocrata -, espelhando-se no modo de viver da aristocracia para alcançar seus objetivos. Seu caminho passa, portanto, pela usurpação e ostentação dos símbolos que caracterizavam a nobreza, parodiando o processo de ascensão dentro de uma sociedade na qual o parecer prevalece sobre o ser. ${ }^{35}$ Para alcançar seus objetivos, o pícaro se vale das suas próprias armas, em especial a astúcia e a trapaça. Tais características permanecem vivas nas releituras da picaresca como, por exemplo, as feitas pelas escritoras chicanas Erlinda Gonzáles-Berry e Ana Castillo, em Paletitas de guayaba e The Mixquiahuala letters, respectivamente, sugerindo que o contexto de exclusão social existente na Espanha do século 16, que deu origem à picaresca, continua presente na contemporaneidade. ${ }^{36}$ No caso do povo chicano, essa exclusão se dá tanto nos EUA, onde é excluído por ser "outro", "estrangeiro", mexicano, mas também no México, onde é visto como pocho, mexicano del otro lado, aquele que não consegue nem mesmo falar espanhol direito. A escritora mexicana Elena

\footnotetext{
${ }^{33}$ QUEIROZ. O herói trapaceiro: reflexões sobre a figura do trickster, p. 94.

34 "Blanche murmurou algumas frases em suáli e iorubá, que ela tinha aprendido na Biblioteca do Harlem, e disse ao rapaz que era uma maldição que tornaria o seu pênis tão fino e pegajoso quanto a língua de uma lagartixa. O olhar dele e o modo como ele segurou a virilha levantaram o ânimo dela consideravelmente. A versão de Nina Simone para "I put a spell on you" ("Eu te enfeiticei") veio então à sua boca, em uma voz profunda e ligeiramente desafinada." (NEELY. Blanche on the lam, p. 38.)

${ }^{35}$ Cf. GONZÁLEZ. A saga do anti-herói. Estudo sobre o romance picaresco clássico espanhol e algumas de suas correspondências na literatura brasileira, p. 72.

${ }^{36}$ Para uma discussão das releituras da picaresca nos romances citados, remeto o leitor a PORTILHO. Contra-escrituras chicanas: revisitando mitos e subvertendo gêneros, p. 65-84.
} 
Poniatowska lembra que os chicanos "estão presos entre dois mundos que os rejeitam: os mexicanos, que os consideram traidores, e os americanos, que só os querem como mão de obra barata". 37

O heroísmo é também uma faceta do trickster que Blanche compartilha. Embora por vezes aja de forma destrutiva, o trickster representa um desejo muito terreno, muito humano, que é o desejo de transgredir. A transgressão do trickster de certa forma sacia esse desejo, sem que seja necessário pagar o preço devido por essa transgressão. Por esse motivo o trickster é visto de forma heroica. Ainda segundo Renato Queiroz, "o ato violador é praticado individualmente - e por isso o trickster é avaliado com sérias restrições enquanto seus resultados são apropriados coletivamente - o que faz dele um herói". ${ }^{38}$

$\mathrm{Na}$ infância, Blanche se chateava quando as outras crianças a chamavam por apelidos como Ink Spot ("Borrão de Tinta") ou Tar Baby ("Boneca de Piche"). Sua prima Murphy então inventa a Night Girl ("Menina da Noite"), uma personagem que, por ser negra, pode se confundir com a noite, e assim transitar livremente, protegida por essa "invisibilidade", um poder quase mágico, característico do trickster:

Some people got night in 'em, some got morning, others, like me and your mama, got dusk. But it's only them that's got night that can become invisible. People who got night in 'em can step into the dark and poof - disappear! Go any old where they want. Do anything. ${ }^{39}$

A Night Girl é uma imagem que subverte o preconceito racial e projeta a pele negra como uma vantagem. A invisibilidade ganha então um tom ambíguo (novamente uma característica do trickster) - deixa de significar falta de importância, e se converte em uma forma de poder, de superioridade. À noite, a Night Girl Blanche é como os super-heróis: tem poderes que as pessoas comuns não têm, como o dom de ver sem ser vista. Assim, ela tem liberdade para agir, e, por consequência, para "bisbilhotar" sem ser notada, como se vê no trecho abaixo:

Night Girl gave Blanche a sense of herself as special, as wondrous, and as powerful, all because of the part of her so many people despised, a part of her that she'd always known was directly connected to the heart of who she was. It was then that she'd become Night Girl, slipping out of the house late at night to roam around her neighborhood unseen. She'd sometimes stop beside an overgrown azalea by a rickety front porch and learn from deep, earnest voices of neighborhood deaths and fights, wages gambled away, about-to-be-imprisoned sons and pregnant daughters, before her mother and her talkative friends had gotten the news. The prior knowledge had convinced Blanche's mother that her child had second sight. ${ }^{40}$

37 "Chicanos are caught between two worlds that rejectthem: Mexicans who consider them traitors, and Americans who want them only as cheap labor." (PONIATOWSKA. Mexicanas and chicanas, p. 37.) (minha tradução)

${ }^{38}$ QUEIROZ. O herói trapaceiro: reflexões sobre a figura do trickster, p. 99.

39 "Algumas pessoas têm em si a noite, outras, a manhã, outras, como eu e a sua mãe, temos o crepúsculo. Mas são só aqueles que têm a noite que podem se tornar invisíveis. As pessoas que têm a noite em si podem sair no escuro e puf - desaparecer! Ir a qualquer lugar que queiram. Fazer qualquer coisa." (NEELY. Blanche on the lam, p. 59.)

40 "A Night Girl dava a Blanche uma noção de si própria como uma pessoa especial, admirável e poderosa, tudo por causa da parte dela que tantas pessoas desprezavam, uma parte que ela sabia estar diretamente ligada a quem ela era no íntimo. Era então que ela se tornava a Night Girl, saindo de casa tarde da noite 
A Blanche adulta reconhece que, como uma empregada doméstica negra, é "invisível" várias vezes, por sua raça, sexo e classe social. Rosemary Hathaway aponta, entretanto, que ela também reconhece o poder potencial dessa invisibilidade, e o utiliza para conduzir e disfarçar suas investigações:

Outros detetives ficcionais poderiam usar perucas e fantasias para se disfarçar, mas o "disfarce" de Blanche é construído por meio dos estereótipos de raça, gênero e classe que a circundam - estereótipos que Blanche consegue explorar e subverter ao fazer o seu trabalho de detetive. ${ }^{41}$

Hathaway argumenta que, para Blanche, essas várias perspectivas são inextricáveis - como trickster, suas ações e percepções se baseiam não apenas na sua consciência racial, mas também na sua consciência de ser mulher e pertencer à classe operária, além de desempenhar, em seu trabalho, um papel tipicamente feminino. Seu trabalho de detetive e suas observações dependem da complexa rede formada por esses múltiplos níveis de consciência. ${ }^{42}$

Por outro lado, Renato Queiroz chama a atenção para o fato de que a transgressão levada a cabo pelo trickster já constitui uma transgressão institucionalizada, autorizada pela sociedade:

O trickster colocaria em jogo, assim, o inesperado, o indefinido, desrespeitando, no nível do imaginário, a própria ordem social. (...) Seu papel seria (...) semelhante ao de outros personagens - bufões, mascarados, bobos da corte - aos quais se concede licença para que possam zombar da ordem estabelecida, "quebrando aparências e desfazendo ilusões". Muito embora as transgressões cometidas por tais figuras sejam autorizadas pela sociedade, a própria ordem acabaria sendo assim reforçada, por meio de um processo catártico, e com o mérito de revelar aos seus integrantes a desordem que poderia se instaurar caso as normas, os códigos e os interditos viessem a se dissolver. Elemento, a um só tempo, perturbador e agente da ordem, decorreria disto a ambigüidade do trickster. ${ }^{43}$

A validade do trecho acima é questionável em relação a Blanche. Embora, como detetive, ela teoricamente personifique um elemento "agente da ordem", cabe lembrar que a ordem que ela representa não é necessariamente a ordem vigente, instaurada pela sociedade branca. Lembra Tim Libretti que as noções de lei e justiça, que costumam ser consideradas sinônimas pelo centro hegemônico, podem não ser coincidentes para a comunidade periférica. Uma vez que a lei é feita para atender aos interesses do centro,

para vagar pela vizinhança sem ser vista. Escondida nos canteiros de azaleias perto das varandas, ela ouvia sobre as mortes e brigas na vizinhança, os salários perdidos no jogo, os filhos prestes a ir para a cadeia e as filhas grávidas, tudo antes que sua mãe e as amigas faladeiras soubessem das notícias. Esse conhecimento prévio tinha convencido a mãe de Blanche de que sua filha tinha visões." (NEELY. Blanche on the lam, p. 59-60.)

${ }^{41}$ HATHAWAY. The signifyin(g) detective: Barbara Neely's blanche white, undercover in plain sight, p. 320.

${ }^{42}$ HATHAWAY. The signifyin $(\mathrm{g})$ detective: Barbara Neely's Blanche White, undercover in plain sight, p. 321.

${ }^{43}$ QUEIROZ. O herói trapaceiro: reflexões sobre a figura do trickster, p. 98. 
ou seja, à manutenção da ordem vigente, muitas vezes ela não é justa com aqueles que se encontram à margem. ${ }^{44}$ Desse modo, servir à justiça, para a população da periferia, não quer dizer necessariamente apoiar o sistema existente.

Além disso, Blanche não é uma detetive profissional; não está, portanto, comprometida com o sistema policial ou com qualquer outra forma de manutenção da lei. Segundo Barbara Neely, Blanche é apenas "uma mulher negra e pobre, da classe operária, que tem que lidar com o que quer que a vida ponha em seu caminho, inclusive alguns cadáveres". ${ }^{45}$ Nos moldes de Miss Marple, ela é uma detetive amadora, autodesignada para resolver os mistérios que surgem em seu caminho - embora às vezes tenha que fazê-lo para salvar a própria pele, na maior parte dos casos é levada pela força da curiosidade e da mais pura bisbilhotice. Seu propósito, entretanto, não é leviano - suas investigações são tratadas como uma forma de reparar o desequilíbrio de poder entre ela própria e seus patrões.

Nota-se que é grande a probabilidade de que os gostos e valores dos leitores para os quais Barbara Neely escreve contradigam ideologicamente os gostos e valores do grande público leitor dos EUA, alinhado com as crenças, valores e atitudes hegemônicas da cultura dominante do país, que é branca.

Maureen Reddy aponta que há certos comentários sobre questões raciais, distribuídos ao longo da série Blanche White Mysteries, que só fazem sentido se forem compreendidos como direcionados aos leitores brancos, como uma forma de instruí-los sobre tais assuntos. ${ }^{46}$ Alguns exemplos dessas "passagens de instrução" se encontram em Blanche among the talented tenth, romance em que Neely trata das dificuldades existentes nas relações entre os negros de pele escura e os de pele clara, indicando a existência de um preconceito intrarracial que passa ao largo do conhecimento dos brancos. Logo no início do romance, ao chegar à Amber Cove, Blanche descreve a reação de Arthur Hill, o gerente, à sua aparência:

Without a word, he placed his hands on the counter, leaned slightly forward and played his eyes over her luggage, shoes and clothes in a way that said who made her clothes and how well she'd whitefied her hair were major issues for him. In the case of someone as black as her, were her clothes and the condition of her hair even more important to him? Something had to compensate. ${ }^{47}$

No trecho abaixo, temos um outro exemplo de como as questões de cor permeiam as relações dentro da própria comunidade negra. Blanche explica por que reage com desconfiança quando Stu demonstra seu interesse por ela:

${ }^{44}$ LIBRETTI. Lucha Corpi and the politics of detective fiction, p. 67.

${ }^{45} \mathrm{Cf}$. CARY. Grandma just liked to boogie.

${ }^{46}$ REDDY. Traces, codes, and clues: reading race in crime fiction, p. 66.

47 "Sem uma palavra, ele apoiou as mãos sobre o balcão, inclinou-se um pouco para a frente e passou os olhos pela sua bagagem, sapatos e roupas de um modo que dizia que quem assinava suas roupas e o quão bem ela tinha embranquecido seus cabelos eram questões fundamentais para ele. No caso de alguém tão negro quanto ela, será que suas roupas e o estado do seu cabelo eram ainda mais importantes para ele? Alguma coisa tinha que compensar." (NEELY. Blanche among the talented tenth, p. 15-16.) 
He was a member of one of those First Black Families. He probably went to private schools and had never seen a cockroach - unless he went south during the civil rights movement. And then there were his looks. He wouldn't be the first light-skinned man who'd thought her blackness meant an automatic trip to paradise in gratitude for his willingness to screw someone as black as her, was how she thought the reasoning went. ${ }^{48}$

Em outro episódio, Blanche surpreende Veronica, uma das hóspedes do resort, em uma farmácia, comprando produtos alisantes para o cabelo. Imediatamente, ela pega suas compras e foge depressa, o que leva Blanche a se perguntar se a mulher teria se incomodado tanto com o fato de uma desconhecida descobrir que ela alisava o cabelo por estar tentando se passar por branca:

The woman snatched her purchases and hurried around the corner. Blanche wondered if she might actually be trying to pass for white.

She tried to imagine having that chance and taking it. She could picture herself a hundred shades lighter with her facial features sharpened up; but she couldn't make up the leap to wanting to step out of the talk, walk, music, food and feeling of being black that the white world often imitated but never really understood. She realized how small a part her complexion played in what it meant to her to be black. ${ }^{49}$

Ao refletir sobre quais características em si mesma a levam a definir-se como negra, Blanche abre um questionamento sobre o significado de ser branco ou negro, inclusive chamando a atenção para o fato de que o branco frequentemente imita o negro - nas roupas e penteados, nos modos de falar e dançar. A imitação do negro pelo branco também carrega uma diferença, mas essa diferença não é vista como uma forma de Significar diferente, e sim como uma incapacidade de compreender verdadeiramente as implicações de ser negro nos EUA da contemporaneidade.

$\mathrm{Na}$ sociedade contemporânea, ser branco, negro, indígena ou pertencente a qualquer raça ou etnia é uma noção fluida, que não obedece a critérios biológicos, mas sim políticos. O branco sabe-se branco por ser parte da sociedade política e culturalmente dominante, distinto dos outros, que, no ponto de vista hegemônico, perdem suas identidades particulares e são homogeneizados e abrigados sob a rubrica "Outro". Nos textos produzidos na periferia do poder, entretanto, vê-se que o branco não ocupa uma posição central, de quem detém o poder. A própria Barbara Neely oferece dois exemplos bastante ilustrativos dessa questão, ambos retirados de Blanche on the lam. No primeiro

\footnotetext{
48 "Ele era membro de uma daquelas Primeiras Famílias Negras. Provavelmente estudou em escolas particulares e nunca viu uma barata - a menos que tenha ido para o sul durante o Movimento pelos Direitos Civis. E tinha também a aparência dele. Ele não seria o primeiro homem de pele clara a pensar que a pele escura dela significava uma viagem automática ao paraíso em gratidão pela boa vontade dele em transar com alguém tão negro como ela, era assim que ela via que o raciocínio funcionava." (NEELY. Blanche among the talented tenth, p. 57.)

49 "A mulher agarrou suas compras e dobrou a esquina com pressa. Blanche se perguntou se ela poderia mesmo estar tentando se passar por branca. / Ela tentou imaginar o que seria ter essa chance e aproveitála. Ela conseguia se ver com a pele centenas de tons mais clara e as feições refinadas; mas ela não conseguia chegar ao ponto de querer deixar para trás o falar, o andar, a música, a comida e o sentimento de ser negra que o mundo branco frequentemente imitava mas nunca entendia de verdade. Ela percebeu que a cor de sua pele desempenhava um papel muito pequeno no que significava para ela ser negra." (NEELY. Blanche among the talented tenth, p. 20.)
} 
exemplo, Blanche percebe que tem, em relação a Mumsfield, o mesmo "sexto sentido" que a alerta quando sua mãe, sua amiga Ardell ou uma das crianças se aproxima:

This thing with him was beyond her Approching Employer Warning Sense, which alerted her to the slightest rustling or clinking of a nearing employer. This was more like the way she always knew when her mother was around, or Ardell, or which one of the children was about to fling open the door and bound through the house. This ability to sense Mumsfield's approach was of the same nature but different. What made it different was the fact that she didn't know this white boy and didn't appreciate having him on her frequency..$^{50}$

Doris Witt faz um paralelo entre esse trecho do romance e a passagem na qual Blanche compara a posição de Mumsfield na sociedade com a posição dos negros, particularmente das mulheres negras. ${ }^{51}$ Blanche conclui que, devido à Síndrome de Down, Mumsfield é tão diferente e, portanto, tão invisível aos olhos da sociedade hegemônica quanto ela própria e, desse modo, "visível ao seu olho interior e merecedor do seu cuidado". ${ }^{52}$ Ainda segundo Witt:

Blanche finalmente justifica o seu investimento emocional em Mumsfield, aceitando a realidade empírica de sua deficiência e designando-o uma mulher negra honorária. Por essa perspectiva, a diferença genética de Mumsfield em relação à masculinidade branca burguesa normativa o torna, paradoxalmente, tão invisível quanto Blanche e, assim, merecedor de ser registrado pelo seu "sexto sentido". 53

Ao conferir a Mumsfield o título de "mulher negra honorária", Blanche leva o leitor a questionar o que significa ser uma "mulher negra" e, por extensão, o que significa ser mulher ou homem, negro ou branco.

No segundo exemplo, Neely introduz uma estratégia de reverter a conotação de que branco equivale a positivo e negro a negativo, ao Significar sobre o sentido de blackmail (chantagem): $:^{54}$

She thought the sheriff's solution included paying someone off with money he expected to get from Everett for not telling Grace that Everett was fucking around. Blackmail, in a word. Blanche quickly searched the mind for the other word, the one that began with "ex". She tried not to use words that made black sound bad. When she couldn't find the

\footnotetext{
50 "Essa coisa com ele estava além do seu Sentido de Alarme para o Patrão que se Aproxima, que a alertava quanto ao menor ruído de um patrão se aproximando. Parecia mais o modo como ela sempre sabia quando sua mãe estava por perto, ou Ardell, ou qual das crianças estava prestes a abrir a porta de repente e irromper pela casa. Essa habilidade de sentir a aproximação de Mumsfield era da mesma natureza, mas diferente. O que a tornava diferente era o fato de que ela não conhecia esse garoto branco e não apreciava tê-lo em sua frequência." (NEELY. Blanche on the lam, p. 45.)

${ }^{51}$ WITT. Detecting bodies: Barbara Neely's domestic sleuth and the trope of the (in) visible woman, p.175.

52 "visible to her inner eye and eligible for her concern". (NEELY. Blanche on the lam, p. 214-215.)

${ }^{53}$ WITT. Detecting Bodies: BarbaraNeely's Domestic Sleuth and the Trope of the (In) visible Woman, p. 175.

${ }^{54}$ A palavra blackmail é formada pela junção de black (negro) e mail (tributo, pagamento). Literalmente, a chantagem seria, portanto, o "tributo negro".
} 
word she wanted, she settled on "whitemale" and was pleased how much more accurately her word described the situation. ${ }^{55}$

A esse respeito, Monika Mueller aponta que Neely reproduz a oposição racial binária entre branco e negro pelo ponto de vista do negro, efetivamente mostrando como, no caso de Blanche, "ser branco significa uma alteridade ao sujeito negro, que requer controle e domínio". ${ }^{56}$

Percebe-se, assim, que, no momento em que o branco é retirado do centro o sentido de autoridade e hegemonia se perde - o que definiria o branco então nesse contexto? Seguindo o raciocínio de que o branco é branco porque não é o Outro, e nesse momento ele é deslocado de sua posição central e passa a ocupar o lugar do Outro, excluído e marginalizado, faz-se necessário um convite à reflexão.

Nesse sentido, Minrose Gwin faz uma contribuição pertinente ao afirmar, em seu ensaio sobre as leituras de textos de mulheres negras por mulheres brancas, que se tal leitura pretende ter algum significado deve dobrar-se sobre si mesma, em um processo reflexivo que não apenas lê suas próprias premissas culturais, mas também volta-se para si própria para ler-se como o outro branco nos textos produzidos por negros. ${ }^{57}$ Como um adendo a essa linha de raciocínio, pode-se considerar também pertinentes as colocações feitas por Doris Sommer, ao analisar a narrativa de testemunho de Rigoberta Menchú, no primeiro exemplo, e as narrativas de escravos dos EUA, em seguida:

Talvez seus silêncios audíveis e suas recusas a conversar sejam calculados não para diminuir a nossa curiosidade, mas para incitá-la e então frustrá-la, levando-nos a sentir que o acesso está fechado e a espantar-nos frente a nossa própria exclusão. ${ }^{58}$

Esses livros resistem ao leitor competente, intencionalmente. Ao marcar uma distância intransponível entre o leitor e o texto, e dessa forma levantar questões de acesso e boasvindas, os escritores (...) praticam estratégias para produzir o tipo de incompetência ao ler que mais leitura não consegue superar. (...) O ponto a ser considerado é a retórica de uma

\footnotetext{
55 "Ela raciocinou que a solução do xerife incluía pagar a alguém com o dinheiro que ele esperava receber de Everett para não contar a Grace que Everett estava galinhando por aí. Chantagem (blackmail), em suma. Blanche buscou depressa na mente a outra palavra, a que começava com 'ex'. Ela procurava não usar palavras que fizessem negro (black) soar mal. Quando não conseguiu encontrar a palavra que queria, ela se decidiu por homem branco (whitemale), e ficou satisfeita ao ver que a sua palavra descrevia a situação de forma bem mais apropriada." (NEELY. Blanche on the lam, p. 122.)

[Neely faz um trocadilho intraduzível entre as palavras mail (correspondência) e male (homem, macho). Assim, blackmail (literalmente a 'correspondência negra') torna-se whitemale (homem branco)]. (N. da T.)

${ }^{56}$ MUELLER. A Cuban American "Lady Dick" and an African American Miss Marple?: the female detective in the novels of Carolina García-Aguilera and Barbara Neely, p. 125.

${ }^{57}$ GWIN. A theory of black women's texts and white women's readings, or... the necessity of being other.

58 "Perhaps Menchú's audible silences and her wordy refusals to talk are calculated not to cut short our curiosity but to incite and then frustrate it, leaving us to feel the access closed off and to wonder at our own exclusion." (SOMMER. Textual conquests: on readerly competence and "minority" literature, p. 144.) (minha tradução)
} 
compreensão seletiva e socialmente diferenciada. O propósito é anunciar o acesso limitado, e não realmente sonegar ou não alguma informação. ${ }^{59}$

Essa "incompetência" de que fala Sommer seria o resultado alcançado pelos romances da série trabalhada aqui, ao permitir essa "compreensão seletiva" e "anunciar o acesso limitado".

Nos romances considerados neste ensaio, a práxis cotidiana assume um papel fundamental como forma de resistência das culturas abordadas frente ao poder dominante; constituem táticas por meio das quais essas comunidades marginalizadas buscam uma (re)apropriação de seus espaços na sociedade - em termos políticos, socioeconômicos e culturais. Conclui-se que, nos romances estudados, a rotina diária se converteu em um modo de re-significar a "invisibilidade" daqueles que se situam à margem da sociedade hegemônica. Ser "invisível" torna-se uma poderosa ferramenta de trabalho, que permite o bom andamento da investigação. As atividades do dia a dia constituem o próprio espaço dessa investigação, onde a detetive busca as pistas para a resolução dos mistérios, o que só é possível porque passa despercebida. Assim, a invisibilidade conduz a um maior acesso ao poder - valendo-se da posição marginal que ocupa, nossa detetive pode questionar uma sociedade a cujas regulações e normas apenas aparentemente se submete.

\title{
A
}

\begin{abstract}
A B STRACT
The practices of everyday life - especially the uses and tactics that characterize the trickster figure - are present in Barbara Neely's Blanche white mysteries series, the object of study of this essay. Michel de Certeau's theory about everyday praxis, developed in The practice of everyday life, is the basis for arguing how these practices take up a new meaning in the confrontation between the center of power and "invisible" groups, as well as their political role as tactics of resistance employed in opposition to dominant social and cultural practices.
\end{abstract}

\section{KEYWORDS}

Detective fiction, counterdiscursive narratives, periphery

\footnotetext{
59 "These books resist the competent reader, intentionally. By marking off an impassable distance between reader and text, and thereby raising questions of access or welcome, writers (...) practice strategies to produce the kind of readerly incompetence that more reading will not overcome. (...) The issue to be considered (...) is the rhetoric of selected, socially diferentiated understanding. Announcing limited access is the point, not whether or not some information is really withheld." (SOMMER. Textual conquests: on readerly competence and "minority" literature, p. 147.) (minha tradução).
} 


\section{REFERÊNCIAS}

CARY, Alice. Grandma just liked to boogie. The Boston Globe, May 9th, 2004. Disponível em: < http://www.wumb.org/about/press/Grandmothershands.doc >. Acesso em: 23 jul. 2006.

CERTEAU, Michel de (1994). A invenção do cotidiano: 1. Artes de fazer. Trad. Ephraim Ferreira Alves. Petrópolis: Vozes, 2005.

DuBOIS, W. E. B. The souls of black folk. Disponível em <http://www.bartleby.com/114> Acesso em: 8 nov. 2008.

ELLISON, Ralph (1952). Invisible man. New York: Vintage, 1995.

GATES Jr., Henry Louis. The signifying monkey: a theory of African American literary criticism. New York: Oxford UP, 1988.

GOELLER, Allison D. An interview with Barbara Neely. In: MUELLER, Monika; FISCHERHORNUNG, Dorothea. Sleuthing ethnicity: the detective in multiethnic crime fiction. Madison: Fairleigh Dickinson University Press; London: Associated University Presses, 2003. p. 299-307.

GONZÁlEZ, Mario M. A saga do anti-herói. Estudo sobre o romance picaresco clássico espanhol e algumas de suas correspondências na literatura brasileira. São Paulo: Nova Alexandria, 1994.

GWIN, Minrose. A theory of black women's texts and white women's readings, or ... the necessity of being other. NWSA Journal, v. 1, n. 1, p. 21-31, 1988.

HATHAWAY, Rosemary V. The signifyin(g) detective: Barbara Neely's Blanche White, undercover in plain sight. Critique, v. 46, n. 4, p. 320-332, 2005.

LIBRETTI, Tim. Lucha Corpi and the politics of detective fiction. In: GOSSELIN, Adrienne Johnson (Ed.). Multicultural detective fiction: Murder from the 'Other' Side. Ed. Adrienne Johnson Gosselin. [Garland Reference Library of the Humanities, v. 2094]. New York: Garland Publishing, 1998. p. 61-81

LYNE, William. The signifying modernist: Ralph Ellison and the limits of double consciousness. PMLA, v. 107, n. 2, p. 319-330, 1992.

MUELLER, Monika. A Cuban American "Lady Dick" and an African American Miss Marple?: the female detective in the novels of Carolina García-Aguilera and Barbara Neely". In: MUELLER, Monika; FISCHER-HORNUNG, Dorothea (Ed.). Sleuthing ethnicity: the detective in multiethnic crime fiction. Madison: Fairleigh Dickinson University Press; London: Associated University Presses, 2003. p. 114-132.

NEELY, Barbara. Blanche on the lam. New York: Penguin, 1992.

NEELY, Barbara. Blanche among the talented tenth. New York: Penguin, 1994.

OLDERMAN, Raymond M. Ralph Ellison's blues and Invisible man. Wisconsin Studies in Contemporary Literature, v. 7, n. 2, p. 142-159, 1966.

PONIATOWSKA, Elena. Mexicanas and chicanas. MELUS, v. 21, n. 3, 1996.

PORTILHO, Carla. Contra-escrituras chicanas: revisitando mitos e subvertendo gêneros. 2004. 100 f. Dissertação (Mestrado em Letras - Literaturas Hispânicas) - Instituto de Letras, Universidade Federal Fluminense, Niterói, 2004. 
QUEIROZ, Renato da Silva. O herói trapaceiro: reflexões sobre a figura do trickster. Tempo Social, Rev. Sociol. USP, São Paulo, v. 3, n. 1-2, p. 93-107,1991. Disponível em: $<$ http://www.fflch.usp.br/sociologia/revistas/tempo-social/v3-1e2/queiroz.html> Acesso em: 21 nov. 2006.

REDDY, Maureen T. Traces, codes, and clues: reading race in crime fiction. New Brunswick, N.J.: Rutgers University Press, 2003.

SCHILLER, Beate. Between Afrocentrism and universality: detective fiction by black women. Disponível em: < http://opus.kobv.de/ubp/volltexte/2005/547/pdf/schiller.pdf>. Acesso em 16 out. 2006.

SOMMER, Doris. Textual conquests: on readerly competence and "minority" literature. Modern Language Quarterly, v. 54, n. 1, p. 141-153, 1993.

TOLSON, Nancy D. The butler didn't do it, so now they're blaming the maid: defining a black feminist trickster through the novels of Barbara Neely. South Central Review, Baltimore, v. 18, n. 3/4, p. 72-85, 2001. Número especial: Whose body: recognizing feminist mystery and detective fiction.

WEATE, Jeremy. Changing the joke: invisibility in Merleau-Ponty and Ellison. Philosophia Africana, v. 6. n. 1, p. 5-21, 2003

WITT, Doris. Detecting Bodies: Barbara Neely's domestic sleuth and the trope of the (in) visible woman. In: BENNETT, Michael; DICKERSON, Vanessa D. (Ed.). Recovering the black female body: self-representations by African American women. New Brunswick, N.J.: Rutgers University Press, p. 165-194. 